\title{
Variables in the Measurement of Serum Cholesterol by Gas-Liquid Chromatography
}

\author{
WIILIAM J. FERRELL, DAVID REPOLA, and JOHN G. BATSAKIS \\ Department of Pathology, University of Michigan Medical Center, Ann Arbor, Michigan 48109, U.S.A.
} (Accepted February 25, 1977)

\begin{abstract}
CLBIA, 10, (3) 118-121 (1977)
Clin. Biochem.

Ferrell, William J., Repola, David, and Batsakis, John G.

Department of Pathology, University of Michigan Medical Center, Ann Arbor, Michigan 48109, U.S.A.

VARIABLES IN THE MEASUREMENT OF SERUM CHOLESTEROL BY GAS-LIQUID CHROMATOGRAPHY
\end{abstract}

Gas-liquid chromatography (GLC) is an effective method for the measurement of total serum cholesterol. Its use in the clinical laboratory, however, requires careful attention to many variables (flow rate, sample size, sensitivity of solvent and choice of the quantitation method, i.e. peak-height ratio vs. peak height). This report evaluates the effect of these variables on the quantitation of serum cholesterol by GLC.

GAS-LIQUid CHROMATOGRAPHY (GLC) is one of the most valuable techniques in sterol and lipid analysis. However, surprisingly little information is available concerning the use of GLC as a routine method for the quantitative analysis of total cholesterol in body fluids. Cawley et al. ${ }^{3 \prime}$ appear to have been among the first to report the use of a quantitative GLC method cesigned exclusively for the purpose of estimating serum cholesterol concentration. Since that report, several alternative methods for cholesterol and other steroids have been described and used in the routine clinical laboratory ${ }^{(2,4-11,13,1-1)}$ Different internal standards, including 11-ketoprogesterone, octacosane, stigmasterol and $5 \alpha$-cholestane have been used. Methods of quantitation also have varied and include the measurement of area, peak heights, and peak-height ratios.

In general, the GLC methods used in clinical diagnostic work demonstrate a satisfactory coefficient of variation with precision studies, correlation coefficients with colorimetric end-point methods of 0.969 or better, and enjoy the advantage of small sample requirements (5-50 y.l.$^{(5,6,13,14)}$

Successful implementation in the clinical laboratory, however, requires control of variables in the technique. The present report deals with several of these variables and presents data showing their effect on the measured total serum concentration of cholesterol.

\section{Materials AND METhods}

Gas-liquid chromatography was carried out using a Barber-Coleman Model 9230 instrument equipped with a dual hydrogen flame detector. A $1.8 \mathrm{~mm} \times 2 \mathrm{~m}$ (ID) stainless steel column, packed with $3 \%$ OV-17 on $100-120$ mesh Gas-Chrom Q, was used isothermally at $260^{\circ}$. Nitrogen was the carrier gas at a flow of $55 \mathrm{ml} / \mathrm{min}$., except for experiments devised to determine the optimum flow rate. Injector and detector temperatures were $290^{\circ}$ and $300^{\circ}$ respectively. The hydrogen flow rate was $30 \mathrm{ml} / \mathrm{min}$. and the air-flow rate was maintained at $375 \mathrm{ml} / \mathrm{min}$.

All reagents and solvents used were Reagent grade. Column packing and $5 \alpha$-cholestane were obtained from Applied Science Laboratories. The internal standard $5 \alpha$-cholestane was selected because of its short (less than $2 \mathrm{~min}$.) retention time and complete resolution is obtained from the cholesterol peak. (See Fig. 1.) Cholesterol was obtained from the National Bureau of Standards (No. 911).

\section{Preparation of Samples}

All samples were prepared essentially by the technique described by Ishikawa, etal(B), and differed only in the selection of the extracting solvent. The ability of several solvents to extract cholesterol and $5 \alpha$-cholestane was investigated using a Dade Lipid-Trol (Lot No. LTT-32) standard. To each $20 \mathrm{ul}$ sample of this material, $20 \mathrm{ug}$ of $5 \alpha$-cholestane internal standard $(20 \mu \mathrm{g} / 100 \mu \mathrm{l})$ were added. After saponification, extractions were performed with 100 ul of solvent. Results are presented in Table 1 and representative chromatograms in Fig. 1. Carbon tetrachloride gave the clearest separation of the two phases. Carbon disulfide and methylene chloride gave essentially identical results. However, since flame ionization detectors are not sensitive to carbon disulfide, it was chosen as the extracting solvent. All subsequent studies in this report were carried out using carbon disulfide as solvent. Phases were separated by centrifugation at $3,500 \mathrm{rpm}$ for 10 minutes. GLC analyses were performed on aliquots of the clear, lower phase.

Before the experimental injections, the column was primed with three $2 \mu$ injections of a standard solution containing $1 \mathrm{ug} / \mathrm{s}, \mathrm{l}$ each of cholesterol and $5 \alpha$-cholestane. This was done to minimize adsorption effects. Subsequently, 3 , l. of the extracting solvents were injected and detectable material was eluted.

\section{Calculations}

For routine clinical work the GLC method requires only four measurements of peak height per injection. The calculations can be based on either a prepared cholesterol standard or a reference serum standard. The actual calculations are as follows:

$$
\frac{\text { Conc. in Samcle }}{\text { Conc. in Reference }}=\frac{\left(\frac{\text { Cholesteral Peak-Height }}{5 \alpha \cdot \text { cnolestane Peak-H. eight }}\right)_{\text {Sample }}}{\left(\begin{array}{l}
\text { Cholesterol Peak-Height } \\
5 \alpha \text {-cholestare 1 eak-F.eight }
\end{array}\right)_{\text {Rerence }}^{\text {Re- }}}
$$

If quantitation is based on peak area this is substituted into the above equation for peak-height. However, it has been shown that the peak-height method is a much more precise measurement technique, ${ }^{(1,12)}$ especially when working with compounds with short retention times, as we 


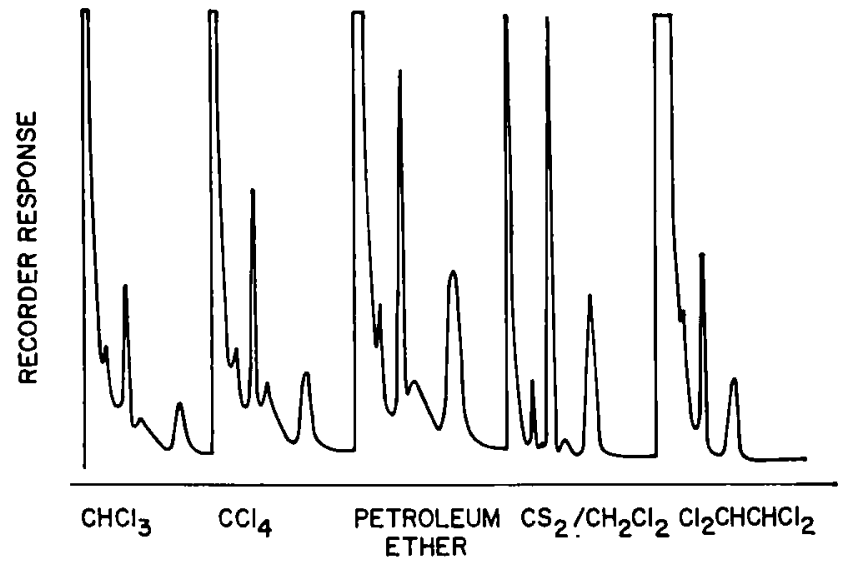

Fig. 1 - GLC traces for total cholesterol and 5 -cholestane following saponification of a Dade Lipid-Trol standard and extraction with various solvents. Column was $3 \%$ OV-17 on Gas-Chrom $Q$ at $260^{\circ}$ with nitrogen as carrier gas at $55 \mathrm{ml} / \mathrm{min}$.

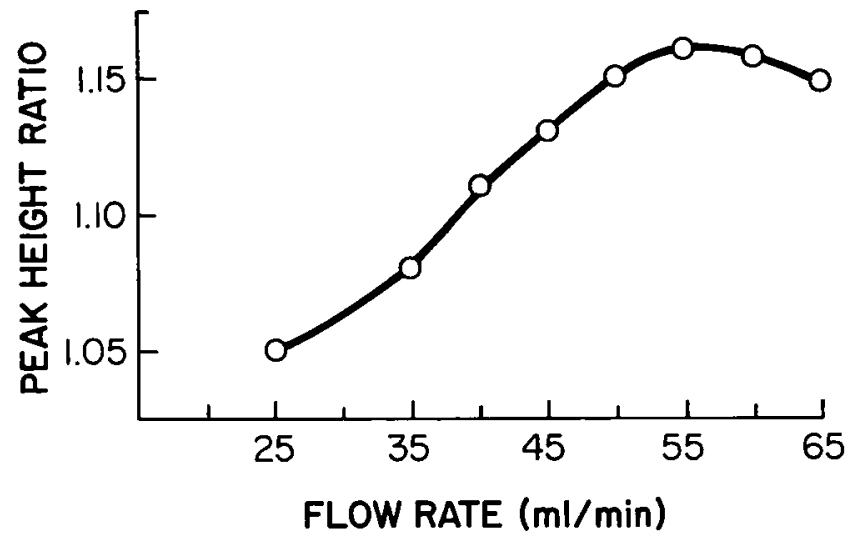

Fig. 3 - The effect of carrier gas $\left(\mathrm{N}_{2}\right)$ flow rate on the peak height ratio of standard cholesterol and 5 -cholestane.

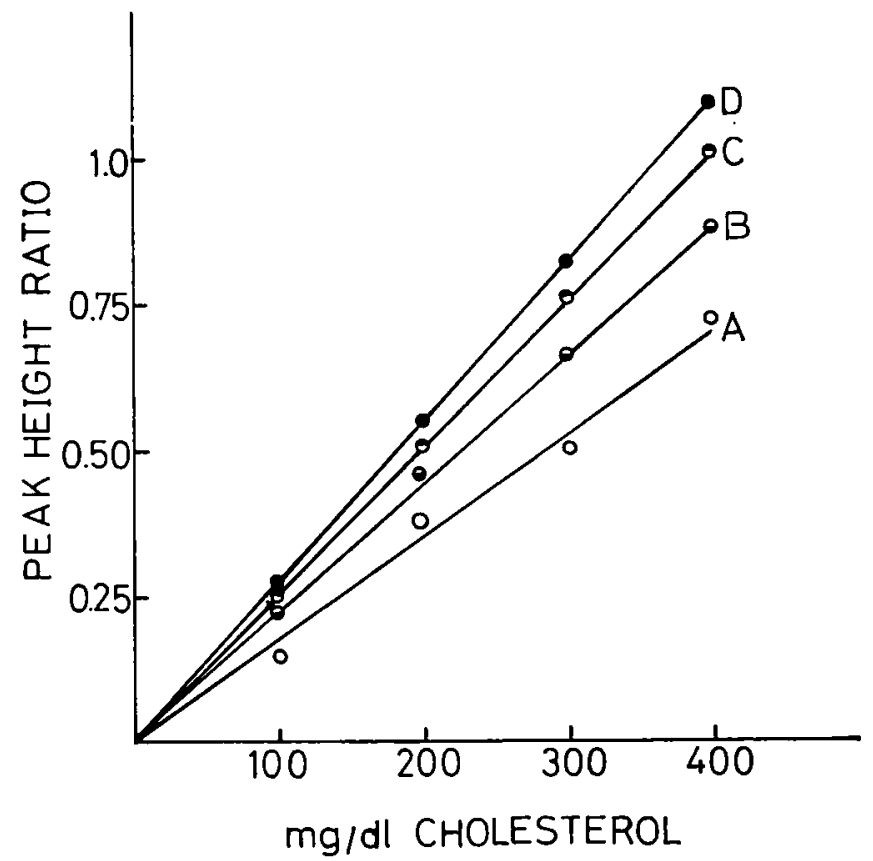

Fig. 5 - Linearity of instrument sensitivity settings to various levels of cholesterol. Sensitivity settings were: $A, 10 ; B, 30 ; C, 300 ; D, 100$.

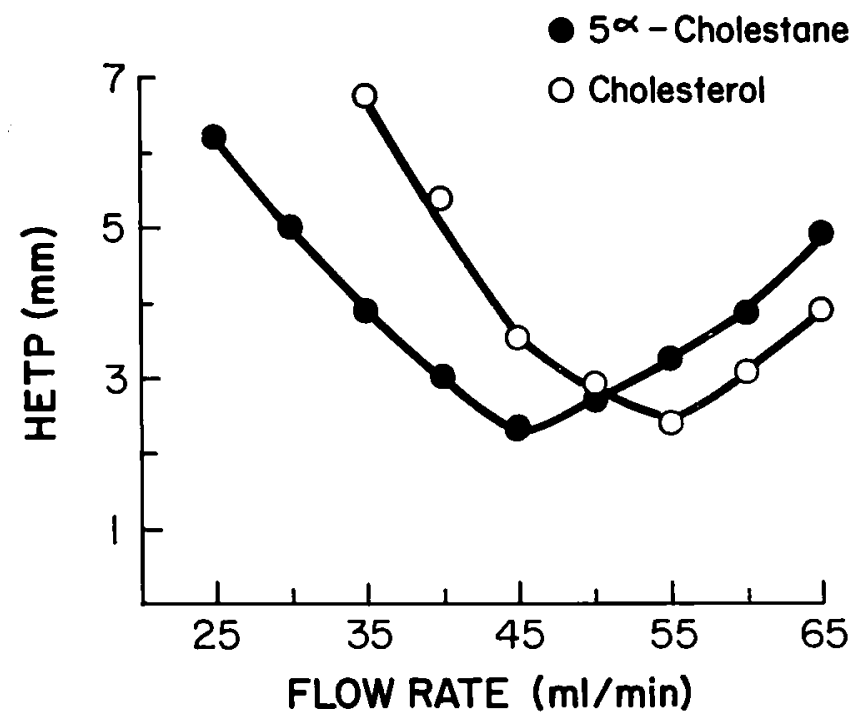

Fig. 2 - van Deemter plot of height equivalent to a theoretical plate (HETP) for $5 \alpha^{- \text {cholestane and choles- }}$ terol.

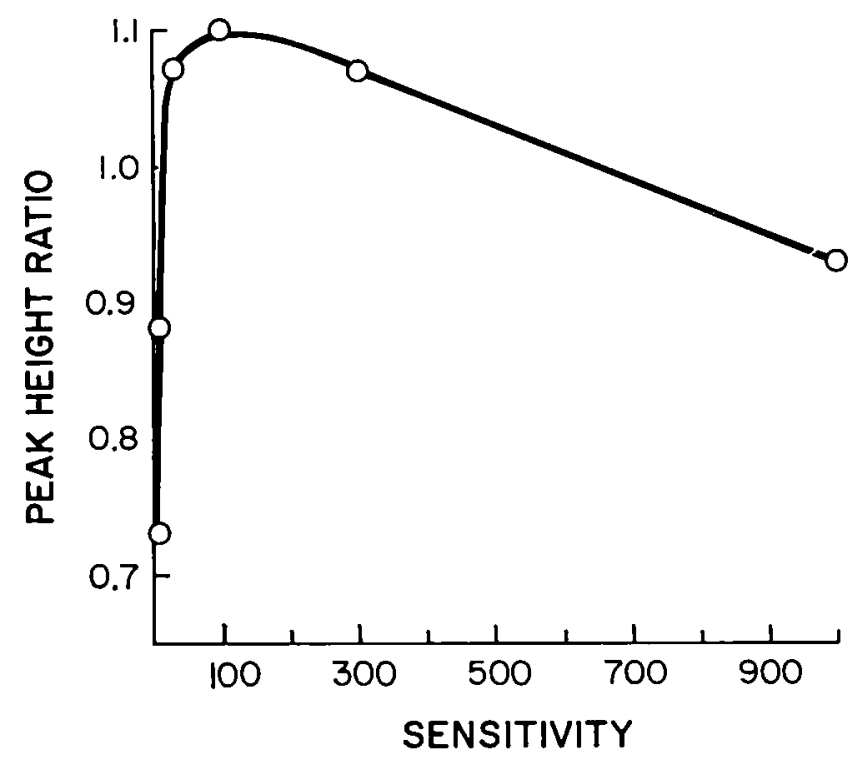

Fig. 4 -- Variation of peak height ratio of standard cholesterol and $5 \alpha$-cholestane with changes in instrument sensitivity setting.

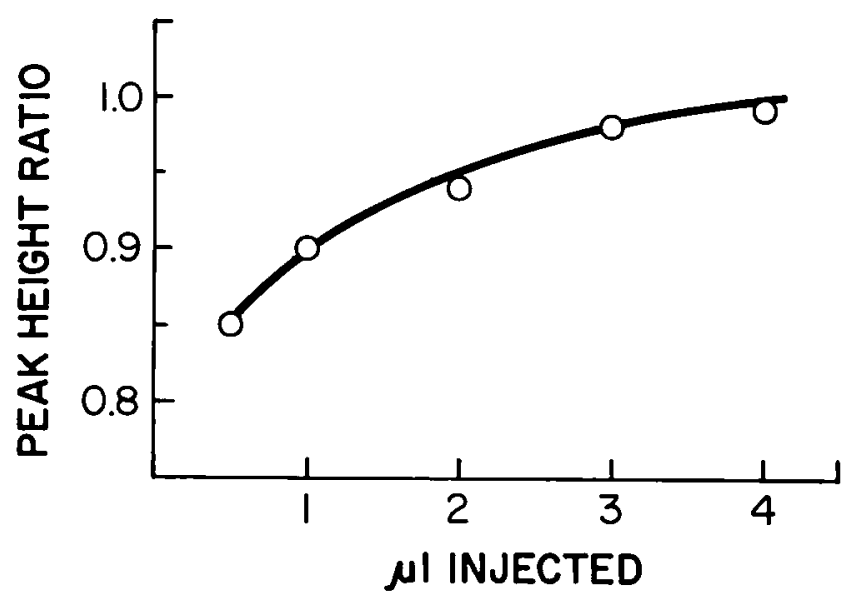

Fig. 6 - The effect of sample size injected on the observed peak-height ratio of standard cholesterol and $5 \alpha$-cholestane. The injected sample was taken from a cholesterol standard containing $40 \mathrm{mg} / \mathrm{dl}$. 


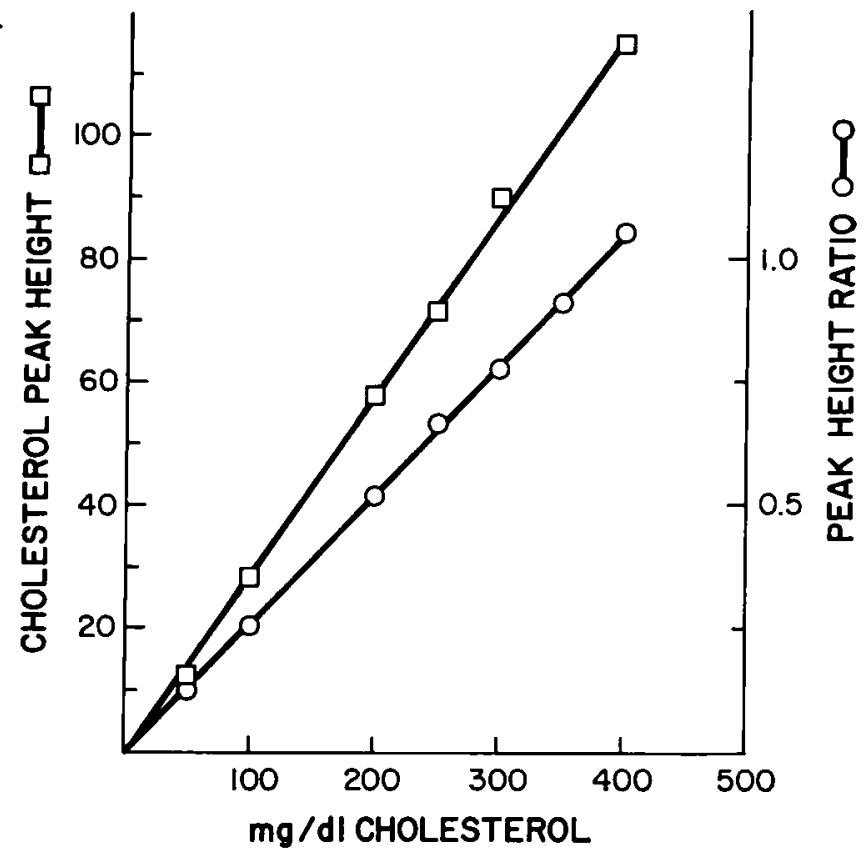

Fig. 7 - Comparison of peak-height measurements for cholesterol to peak-height ratio measurement of cholesterol and 5 -cholestane.

are in this study. For routine cholesterol quantitation, peak-height measurement has been the method of choice for most works. ${ }^{(2,5,8,6,13,14)}$

\section{RESULTS}

Varying the carrier gas-flow rate produced the results shown by the van Deemter plot in Fig. 2. The smallest Height Equivalent to a Theoretical Plate (HETP) for cholesterol was obtained at $55 \mathrm{ml} / \mathrm{min}$ : for $5 \alpha$-cholestane, it was at $45 \mathrm{ml} / \mathrm{min}$. These results suggest that the flow rate has an effect on the resulting peak-height ratio of cholesterol: $5 \alpha$-cholestane. Data presented in Fig. 3 confirm this impression. An optimum peak-height ratio was obtained at $55 \mathrm{ml} / \mathrm{min}$. Since this coincided with the smallest HETP for cholesterol, this flow rate was selected for all subsequent studies.

The peak-height ratio was even more dramatically affected by the sensitivity setting of the instrument (Fig. 4). Similar, although not identical, curves were obtained using two additional instruments, a Packard Model 7800 and a Hewlett-Packard Model 402. In all cases, flame ionization detectors were used and the columns were the same and operated at their optimum flow rates. All three instruments gave an optimum setting which varied between 100 and 300 . On our instrument, optimum ratios were obtained at a setting of 100. This produces a full-scale output into a $1 \mathrm{mv}$ recorder of $2 \times 10^{-10}$ amperes. The linearity of response to various levels of cholesterol was examined at each sensitivity setting. These results are shown in Fig. 5.

Fig. 6 shows the variations in peak height produced by changes in the amount of injected sample. A leveling effect appears with a sample size of $4 \mu \mathrm{rl}(40$ $\mathrm{mg} / \mathrm{dl})$. The injection of a $5 \mu l$ sample caused the flame to blow out. When the initial cholesterol concentration was increased to $100 \mathrm{mg} / \mathrm{dl}$ and higher, essentially linear peak-height ratios were obtained over the 1-4 $\mu$ l range. A typical cholesterol standard curve is presented in Fig. 7. This curve was determined at the optimum sensitivity setting. Since peak heights can be also used as quantitative measurements, a comparison in the Fig. was made between this method and the peak-height ratio method. A linear response was obtained by both methods using samples containing from $50 \mathrm{mg} / \mathrm{dl}$ to $400 \mathrm{mg} / \mathrm{dl}$ of cholesterol. Each point represents the average of five injections. A slightly better curve fit is obtained by the use of peak-height ratio calculations.

Table 1 and Fig. 1 shows that while solvent changes do not significantly effect the cholesterol: $5 \alpha$-cholestane peak-height ratios, the component peak heights are increased, in some instances by almost four fold.

\section{Discussion}

Variations in the van Deemter plots for cholesterol and $5 \alpha$-cholestane account for the changes in their peak-height ratios with carrier gas-flow rate. Reference to Fig. 3 will demonstrate that at the extreme ends of $25 \mathrm{ml} / \mathrm{min}$. (ratio of 1.05) compared to the $55 \mathrm{ml} / \mathrm{min}$. (ratio of 1.16 ), the difference in the calculated $\mathrm{mg} / \mathrm{dl}$ of cholesterol would be $55 \mathrm{mg} / \mathrm{dl}$. The nearer one operates to the optimum flow rate, the smaller this difference becomes. For day-to-day reproducibility, a constant flow rate should be maintained.

Choice of the proper sensitivity selection is more critical (Fig. 4). Again, comparing peak-ratio values from Fig. 4 to the standard curve in Fig. 6, we observe maximum variations with changes in sensitivity that correspond to $148 \mathrm{mg} / \mathrm{dl}$ of cholesterol. It is known that responses of the flame ionization detector are different for various organic solutes, in this case cholesterol and $5 \alpha$-cholestane. The sensitivity setting experiment shows that these differences can vary even more with electronic settings. We see that at the higher sensitivity settings the variation becomes smaller while with the lower sensitivity settings a combination of effects is at work, i.e., the non-linearity of the response to low levels of material ${ }^{(10)}$ and the poor precision involved with measuring very small peaks. Thus, the results show that for routine work one needs to work at a setting which will give sufficiently large peak heights and that given the choice between diluting a more concentrated sample or

\section{TABLE}

EXTRACTION OF CHOLESTEROL AND $5 \alpha$-CHOLESTANE WITH VARIOUS SOLVENTS

\begin{tabular}{|c|c|c|c|}
\hline \multirow{3}{*}{$\begin{array}{l}\text { Solvents } \\
\text { Choloroform .... } \\
\text { Carbon Tetra- } \\
\text { chloride....... }\end{array}$} & \multicolumn{2}{|c|}{$\begin{array}{c}\text { Peak Height (mm) } \\
\text { Cholesterol } 5 \alpha \text {-Cholestane }\end{array}$} & \multirow{2}{*}{$\begin{array}{c}\begin{array}{c}\text { Ratio } \\
\text { Cholesterol/ } \\
5 \alpha \text {-Cholestane }\end{array} \\
0.40\end{array}$} \\
\hline & 13.5 & 34.0 & \\
\hline & 20.0 & 58.5 & 0.34 \\
\hline $\begin{array}{l}\text { ethylene } \\
\text { Petroleum Ether }\end{array}$ & $\begin{array}{l}21.0 \\
43.0\end{array}$ & $\begin{array}{l}47.0 \\
94.0\end{array}$ & $\begin{array}{l}0.45 \\
0.46\end{array}$ \\
\hline $\begin{array}{l}\text { Carbon Disul- } \\
\text { fide.......... }\end{array}$ & 50.0 & 120.0 & 0.42 \\
\hline $\begin{array}{c}\text { Methylene } \\
\text { Chloride. }\end{array}$ & 51.0 & 120.0 & 0.42 \\
\hline
\end{tabular}


changing the established sensitivity setting and reinjecting one should dilute the sample. While linearity between sensitivity settings was not obtained, we did find that at a given setting the response to $5 \alpha$-cholestane and various cholesterol levels was linear (Fig. 5 and 6). For both intra and interlaboratory reproducibility, one needs to establish the detector sensitivity response and do any comparison studies at the maximum response setting.

Sample size can affect both peak width and retention time. With an excess of solute, the solubility in the liquid phase is exceeded, resulting in square topped peaks. Since this happens only at the inlet end of the column, the effect may not be obvious from inspection of the peaks due to a spreading during passage through the column. Nevertheless, it has been shown that an increase in solute leads to an increase of its solubility in the liquid phase, in turn producing a broadened peak. ${ }^{(15)}$ Data from the present study indicates that peak-height ratios change with sample size (Fig. 5). The magnitude of this change is approximately a $14 \%$ difference in cholesterol concentration over the range of $0.5 \mu \mathrm{l}$ to $4 \mu \mathrm{l}$ of injected sample, representing from 0.2 to $1.6 \mu \mathrm{g}$ cholesterol. The nonlinearity at low levels of cholesterol indicate that adsorption could be a problem that needs to be taken into account when the sample contains much less than $50 \mathrm{mg} / \mathrm{dl}$. Similar results were reported by others ${ }^{(7)}$ using the trimethylsilyl ether derivative of cholesterol and $5 \alpha$-cholestane. Should this problem of low cholesterol levels be encountered, it is a simple matter to concentrate the extracted solution by evaporation under nitrogen.

Peak-height ratios do not change significantly with the various solvents tested (Table 1 and Fig. 1). The advantage in our choice of solvent lay in an increased sensitivity (a four-fold increase in extracted cholesterol and $5 \alpha$-cholestane). Additionally, the flame ionization detector is insensitive to carbon disulfide and thus work done at a high sensitivity setting does not have a large solvent peak as an interfering factor.

It is concluded that GLC can be an effective method for the quantitation of serum cholesterol, provided that the many variables such as flow rate, sample size and sensitivity are well controlled.

\section{REFERENCE}

1. Ball, D. L., Harris, W. E., and Habgood, H. W. (1968). Anal. Chem. 40, 129-134.

2. Blomhoff, J. P. (1973). Clin. Chem. Acta 43, 257-265.

3. Cawley, L. P., Musser, B. O., Campbell, S., and Faucette, W. (1963). Am. J. Clin. Pathol. 39, 450-455.

4. Crotte, C., Mule, A., and Planche, N. E. (1970). Clin. Chem. Acta 27, 331-337.

5. Driscoll, J. L., Aubuchon, D., Descoteaux, M., and Martin, H. F., (1971). Anal. Chem. 43, 1196-1200.

6. Harris, P. A., and Harris, K. L. (1974). J. Pharmaceut. Sci. 63, 781-784.

7. Horning, E. C., and Vanden Heuvel, W. J. A. (1965) Adv. In Chromatog., 1, 153-198. Ed. by J. C. Giddings and R. A. Keller. (Marcel Dekker Press N.Y.)

8. Ishikawa, T. T., MacGee, J., Morrison, J. A., and Glueck, C. J. (1974). J. Lipid Res. 15, 286-291.

9. James, A. T. (1963). Methods of Biochem. Anal. Ed. by D. Glick, 8, 1-59. (Interscience Press, N.Y.)

10. Kuksis, A., Stachnyk, O., and Holub, B. J. (1969) J. Lipid Res. 10, 660-667.

11. Kuksis, A., Myher, J. J., Maral, L., and Geher, K. (1975). J. Chrom. Sci. 13, 423-430

12. Littlewood, A. B. (1964). J. Gas Chromatog. 2, 186191.

13. MacGee, J., Ishikawa, T., Miller, W., Evans, G., Steiner, P., and Glueck, C. J. (1973). J. Lab. Clin. Med. 82, 656-662.

14. Morin, R. J., and Elms, N. J. (1975). Ann. Clin. Lab. Sci. 5, 52-56.

15. Weinstein, A. (1969). Anal. Chem. 33, 18-22. 